\title{
Robert Bárány (1876-1936): The Nobel Prize-winning prisoner of war
}

\author{
Adam Bracha ${ }^{1}$, MD, Siang Yong $\underline{T a n}^{2}$, MD, JD
}

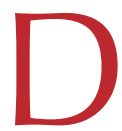
uring World War I, prisoner-of-war camps overseen by the Russian Army held hundreds of thousands of captured servicemen under the harshest of conditions. Interred in one of these camps in central Asia was an Austrian physician, Robert Bárány. It was during his time as a prisoner of war that he learned of his selection for the 1914 Nobel Prize in Physiology/Medicine. For a man who once had "no great expectations regarding [his] future," Bárány would live a remarkable life.

EARLY YEARS The eldest of six children, Bárány was born on April 22, 1876, near Vienna, Austria-Hungary, to Ignáz Bárány, a Jewish bank official, and Marie Hock, the daughter of a respected scientist. Despite contracting tuberculosis of the bones that left Bárány with permanent knee stiffness, he was an active youth. He would later ascribe his early interest in medicine to this experience.

Bárány excelled in his studies throughout his early life and graduated with honours in 1894. He matriculated at the University of Vienna, Austria, and received his medical diploma six years later. After graduating in 1900, Bárány pursued training in internal medicine, neurology, and psychiatry. He returned to Vienna in 1903, and for a time was a student of Sigmund Freud. Later that year, he completed a surgical preceptorship in otology with Professor Adam Politzer, the father of Austrian otology, at the General Hospital of Vienna Ear Clinic. The decade-long collaboration between the two allowed Bárány to pursue his interests in both neurology and surgery.

THE CALORIC RESPONSE Bárány's research focused on the pathophysiology of the vestibular apparatus. At the time, treatment of ear infections involved irrigating the external auditory canals with a syringe. An astute clinician, Bárány noted that some patients experienced dizziness accompanied by nystagmus during this procedure. He discovered the explanation for this phenomenon by a stroke of good luck, when a patient complained, "I only get giddy when the water is not warm enough, but when I do my own ears at home and use warm enough water I never get giddy." Bárány then requested warmer water from his nurse, and resumed the procedure. However, with the use of the warmer water, the patient exclaimed, "But Doctor, this water is much too hot and now I am giddy again." Nystagmus redeveloped, but in the opposite direction. "It came to me then in a flash," Bárány recounted during his Nobel Prize acceptance speech, "obviously the temperature of the water was responsible for the nystagmus." To confirm this, he used body-temperature water to syringe the patient's ears and the patient experienced neither nystagmus nor vertigo. Bárány termed the neurologic response to water of different temperatures the 'caloric response'.

Bárány reflected upon this phenomenon for some time: "then, one day, I had an idea. I remembered the bath water tank and my surprise, as a child, at finding the water immediately above the fire quite cold, whereas higher up, at the top, the tank was so hot that it burned one's finger. The labyrinth reminded me of a bath-water tank." Bárány theorised that, like bath water, endolymph within the semicircular canals sinks when cooled and rises when warmed, due to changes in the specific gravity of the fluid. Temperature-induced displacement of the endolymph might then provide proprioceptive information to the brain via the vestibular nerve. His discovery formed the basis of the Bárány test for diagnosing neurological and middle-ear disease.

Several other researchers had investigated vertigo and nystagmus before Bárány. In 1825, Jean Pierre Flourens observed that destruction of a pigeon's semicircular canals led to bizarre turning and somersaulting behaviour. Johann Evangelist Purkinje proved that changes in head position could induce vertigo. In 1861, Prosper Ménière proposed that vertigo could be related to dysfunction of the vestibular apparatus, not just the cerebellum, and in 1870, Friedrich Goltz concluded that the semicircular canals functions to maintain balance. Finally, in 1874, Josef Breuer, Ernst Mach and Alexander Crum Brown concluded that the semicircular canal is the sensory organ responsible for the perception of rotary motion, and that vertigo is the result of abnormal excitation of the vestibular system. However, it was Bárány who was the first to link these observations together, at the same time recognising the clinical utility of his caloric response test. If the reaction to the test was positive, the canals were deemed to be excitable and therefore intact, but if negative, then the canals were deemed to have been destroyed (albeit with a few exceptions). The caloric response test thus provided a basis by which clinicians could evaluate and develop treatment for inflammatory labyrinth diseases. Bárány

${ }^{1}$ Research carried out during transitional residency, John A Burns School of Medicine, University of Hawaii, Honolulu, USA, ${ }^{2}$ Professor Emeritus of Medicine, University of Hawaii, Honolulu, USA

Correspondence: Prof Tan Siang Yong, 2230 Liliha Street, Suite 104, Honolulu, HI 96817, USA. siang@hawaii.edu 
also developed tests to evaluate equilibrium disorders that probed the relationship between the cerebellum and the labyrinth. In Purkinje's era, treatment of violent behaviour in the mentally ill involved rotating them in a cage until they were quietened by the nausea. Purkinje thought the brain was directly stimulated by the rotation, but Bárány showed otherwise.

A CELEBRITY PRISONER During World War I, Bárány served as a voluntary civilian surgeon in the Austrian army, and his care of intracranial gunshot wounds furthered his research into the cerebellum and vestibular system. His work, however, ceased in 1914 when the Russians captured Bárány and his unit at Przemyśl, and he was transported by cattle car along with other prisoners to the town of Merv in central Asia. However, as his reputation was known to the camp medical commander, Bárány's fate was considerably more fortunate than the other prisoners - Bárány was promptly charged with directing the otolaryngology service for both Austrian prisoners and their Russian captors. Indeed, Bárány treated the local mayor and his family, and became a regular dinner guest in their home.

RETREAT FROM THE SPOTLIGHT Bárány received the 1914 Nobel Prize in Physiology/Medicine after being nominated on seven prior occasions for his work on the physiology and pathology of the vestibular apparatus of the ear. The telegram notifying him of his award did not reach him until 1915, and it was only upon the personal intervention of Prince Carl of Sweden that Tsar Nicholas I arranged for Bárány to be released from the prison camp in 1916. Bárány's joy was short-lived, however. Following his release, he was accused of plagiarism and scientific omission by some of his Viennese colleagues. An investigation by the Karolinska Institute absolved him of the charges, and a number of famous Swedish otologists published a paper in his defence. A Vienna newspaper published a cartoon of Bárány with his Nobel laurel, captioned "I have succeeded in curing all kinds of ear injuries but the deafness of the Vienna faculty." However, stung by the accusations, Bárány abandoned his academic plans at the University of Vienna, and instead emigrated to Sweden to become the chief of otological services at the University of Uppsala.

It is likely that Bárány's personality contributed to the conflict with his colleagues. "I was often told when I was 14 or 15 years old that I was very self-centred," he recalled. He was quiet and quite combative, and could come across as aloof or standoffish. Bárány enjoyed telling a story from his days of working with Sigmund Freud. The famous psychotherapist was known for his theory that dreams were manifestations of unconscious desire. On one occasion, Bárány described a dream to Freud that did not appear to reveal any latent desire. "That is very simple," demurred Freud, "you had the desire to contradict me."

PRIVATE LIFE Despite his childhood knee condition, Bárány managed to be an avid hiker and tennis player. He enjoyed music and could play the piano well. Marrying Ida Berger in 1909, the couple had three children, all of whom became physicians or medical scientists. However, the move to Uppsala, Sweden, in 1917 was not easy on the family. They had to learn the Swedish language and adjust to the new environment - Bárány's wife missed Vienna, and felt that Uppsala lacked culture. Bárány remained active in research and surgery, devoting his energy to developing a new otolaryngology clinic at the University. In 1921, he described the phenomenon of benign positional vertigo, relating it to a disorder of the otoliths, and in 1926, he was promoted to full professor. Bárány was also an active pacifist, probably because of his personal experience as a military surgeon and prisoner-of-war. His efforts led to the 1929 founding of the International Academy of Politics and Social Science for the Promotion of World Peace.

Bárány's final years were difficult. He sustained multiple strokes, which resulted in partial paralysis and caused him excruciating thalamic pain. On April 8, 1936, he suffered a last, fatal stroke. He died in Uppsala two weeks before a planned scientific conference to honour his 60th birthday.

\section{BIBILIOGRAPHY}

- Baloh RW. Robert Bárány and the controversy surrounding his discovery of the caloric reaction. Neurology 2002; 58:1094-9.

- Cosimi AB. Surgeons and the Nobel Prize. Arch Surg 2006; 141:340-8.

- Firkin BG, Whitworth JA. Dictionary of Medical Eponyms. New York: Parthenon Publishing, 1996.

- Marx G. Conflicts and Creativity - The Hungarian Lesson. Budapest: Hungarian Academy of Sciences, 1998.

- Nobelstiftelsen. Physiology or medicine. New York: Published for the Nobel Foundation by Elsevier, 1964.

- Pearce JM. Robert Bárány. J Neurol Neurosurg Psychiatry 2007; 78:302.

- Pearce JM. Benign paroxysmal vertigo, and Bárány's caloric reactions. Eur Neurol 2007; 57:246-8. 